\title{
Pneumothorax, pneumomediastinum and subcutaneous emphysema following closed percutaneous pleural biopsy: a case report \\ KB Sriram* and HPA Jersmann
}

\author{
Address: Department of Thoracic Medicine, Royal Adelaide Hospital, Adelaide, South Australia 5000, Australia \\ Email: KB Sriram* - bajeekrishna@gmail.com; HPA Jersmann - hubertus.jersmann@health.sa.gov.au \\ * Corresponding author
}

Published: 25 October 2008

Cases Journal 2008, I:274 doi:10.1 I86/1757-1626-1-274

This article is available from: http://www.casesjournal.com/content/I/I/274

(C) 2008 Sriram and Jersmann; licensee BioMed Central Ltd.

This is an Open Access article distributed under the terms of the Creative Commons Attribution License (http://creativecommons.org/licenses/by/2.0), which permits unrestricted use, distribution, and reproduction in any medium, provided the original work is properly cited.
Received: I5 September 2008

Accepted: 25 October 2008

\section{Background}

Malignant pleural effusions typically indicate disseminated disease, with an expected median survival of 3-12 months [1,2]. Prognosis is particularly poor when the pleural effusion is due to primary lung cancer $[1,2]$. There are several techniques available to investigate suspected malignant pleural effusions, ranging from simple procedures, such as pleural fluid aspiration and closed percutaneous pleural biopsy (CPB), to more complicated procedures, such as thoracoscopy. Guidelines for the diagnosis of unilateral pleural effusions typically recommend using minimally invasive investigations to obtain a diagnosis when malignancy is suspected [1]. We report a patient with an exudative unilateral pleural effusion who underwent a CPB and suffered a severe complication of this procedure.

\begin{abstract}
nimally invasive investigations, such as pleural fluid cytological assessment and closed most cases; however closed pleural biopsy is performed to increase the diagnostic yield when pleural fluid cytology is negative. This additional yield is at the expense of increased complication rates. We report a 64-year old man with a negative pleural fluid cytology but suspected malignant pleural effusion who underwent a closed pleural biopsy, which was complicated by pneumothorax, pneumomediastinum and severe subcutaneous emphysema. Pulmonary laceration by the pleural infrequent but significant complication of closed percutaneous pleural biopsy.
\end{abstract}

\section{Case report}

A 64-year-old-man was referred to our institution for investigation of a large left pleural effusion. Over the preceding two months, he had developed progressive dyspnea, left pleuritic chest pain and $6 \mathrm{~kg}$ weight loss. He was a reformed smoker with a 40-pack-year smoking history. He was admitted to the hospital, and a thoracic CT scan (Figure 1) was performed which showed a large left pleural effusion, left lung collapse and a left lower lobe mass. Pleural fluid cytology did not contain any malignant cells. Subsequently, CPB using Abrams needle was performed by a senior medical officer. Three out of four specimens contained normal pleural tissue without any malignant features.

Twelve hours after the procedure, he developed a high pitched dysphonia, severe dyspnea, and pleuritic left chest 


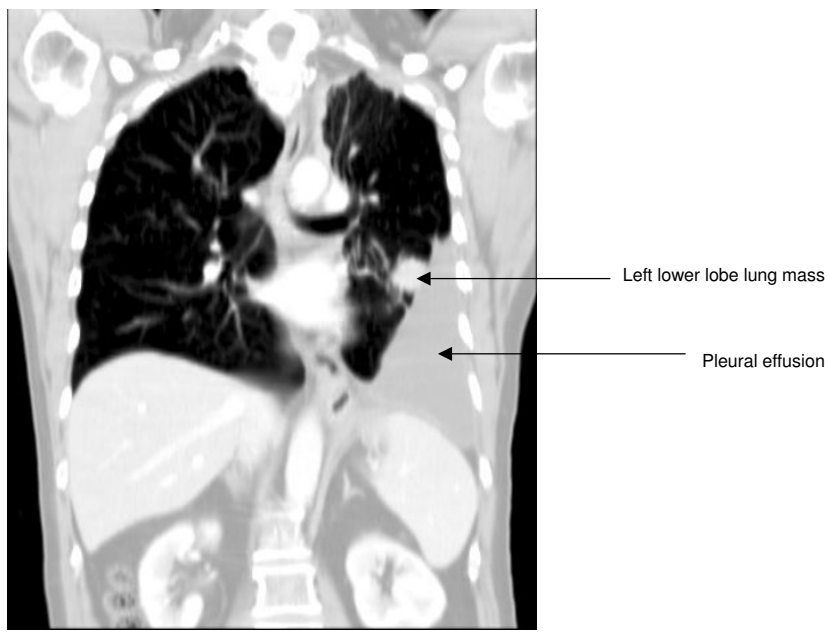

Figure I

Coronal view of thoracic computed tomography scan showing large left pleural effusion and mass in the left lower lobe.

pain. On examination, there was extensive subcutaneous emphysema along the chest wall extending to the neck. An emergency thoracic CT scan (Figure 2) was performed, which revealed subcutaneous emphysema, pneumothorax and pneumomediastinum. An intercostal chest tube was inserted, resulting in complete resolution of the pneumothorax. The subcutaneous emphysema, dysphonia and pneumomediastinum were resolved in seven days. The chest tube was successfully removed after seven days.

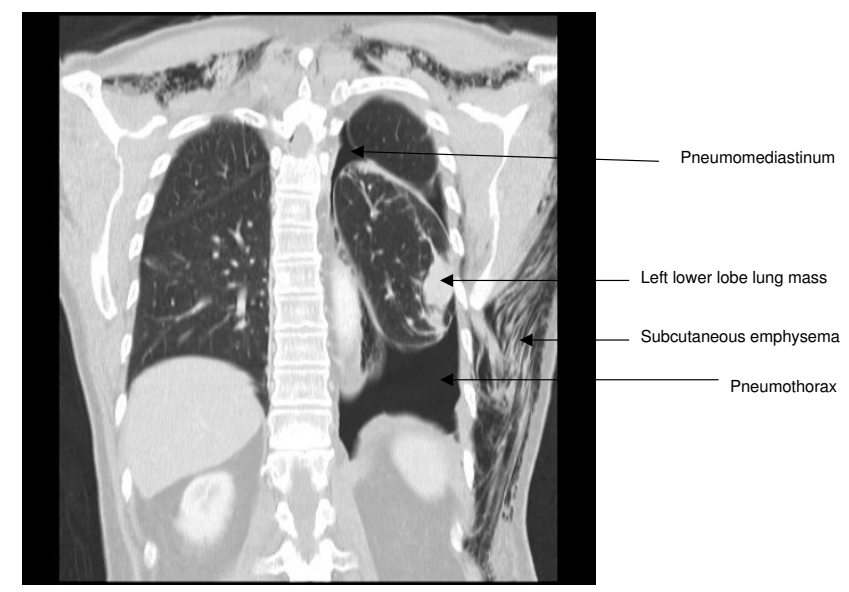

Figure 2

Coronal view of thoracic computed tomography scan showing pneumothorax, pneumomediastinum and subcutaneous emphysema which developed after iatrogenic pulmonary injury caused by Abrams pleural biopsy needle.
Subsequently, a CT guided FNA of the left lower lobe mass was obtained. This revealed non-small cell lung cancer, subtype adenocarcinoma. The patient is currently receiving palliative chemotherapy with symptomatic improvement and no recurrence of the pleural effusion.

\section{Discussion}

Malignant pleural effusions can be diagnosed by pleural fluid cytology alone in $60 \%$ of cases, and CPB can increase the diagnostic yield by $7 \%-27 \%$ [1]. Pleural biopsies are performed using either an Abrams' or Cope needle and can be successfully performed with limited training [[1,3], and [4]]. Pneumothorax develops in $3-15 \%$ of patients undergoing $\mathrm{CPB}$, and of these patients, $1 \%$ requires chest tube drainage $[1,3,4]$. Pneumomediastinum and subcutaneous emphysema after $\mathrm{CPB}$ has not been commonly reported.

Pneumothorax most commonly develops due to entry of air through the biopsy needle or laceration to the lung parenchyma. We hypothesize that in our patient, laceration to the lung parenchyma rather than air entry through biopsy needle is the most likely pathogenetic mechanism. The injury probably produced a bronchopleural fistula, allowing air to track along the continuum between the endothoracic fascia of outer chest wall, pleural space and mediastinum, resulting in subcutaneous emphysema, pneumothorax and pneumomediastinum [5]. We believe that air in the subcutaneous tissues of the neck caused the patient's dysphonia, because as the subcutaneous emphysema resolved so did the dysphonia.

Because of the limited yield and risk of complications, CPB has been superseded by thoracoscopy in some centers. Thoracoscopy is diagnostic in $95 \%$ of malignant pleural effusions [6,7]. The high yield is due to the direct visualisation of the pleura and the ability to obtain large biopsy specimens from abnormal pleura. Additionally, thoracoscopy can be used to perform talc pleurodesis, producing effective symptom palliation [6,7]. However, the procedure is expensive, requires highly trained operators and is not widely available.

Our report illustrates the complications of pneumothorax, pneumomediastinum and subcutaneous emphysema after a non-diagnostic CPB. We believe that by being aware of the limitations of $\mathrm{CPB}$, clinicians can better choose the appropriate test in the investigation of exudative unilateral pleural effusions.

\section{Consent}

Written informed consent was obtained from the patient for publication of this case report and accompanying images. A copy of the written consent is available for review by the Editor-in-Chief of this journal. 


\section{Competing interests}

The authors declare that they have no competing interests.

\section{Authors' contributions}

KBS reviewed the case notes and prepared the manuscript. HPAJ read and approved the final manuscript.

\section{References}

I. Maskell NA, Butland RJA: BTS guidelines for the investigation of a unilateral pleural effusion in adults. Thorax 2003, 58 Suppl 2:ii8-iil 7.

2. Antunes G, Neville E, Duffy J, Ali N: BTS guidelines for the management of malignant pleural effusions. Thorax 2003, 58 Suppl 2:ii29-ii38.

3. Chakrabarti B, Ryland I, Sheard J, Warburton CJ, Earis JE: The roles of Abrams percutaneous pleural biopsy in the investigation of exudative pleural effusions. Chest 2006, I 29:1549-1555.

4. Baumann MH: Closed Pleural Biopsy: Not Dead Yet! Chest 2006, I 29:1398-1400.

5. Murray, Nadel's : Textbook of Respiratory Medicine. 4th edition. Elsevier Saunders; 2005.

6. Lee $P, C o l t ~ H G$ : Rigid and semirigid pleuroscopy: The future is bright. Respirology 2005, 10:418-425.

7. Rodriguez-Panadero F, Janssen JP, Astoul P: Thoracoscopy: general overview and place in the diagnosis and management of pleural effusion. Eur Respir J 2006, 28:409-42I.

Publish with Bio Med Central and every scientist can read your work free of charge

"BioMed Central will be the most significant development for disseminating the results of biomedical research in our lifetime."

Sir Paul Nurse, Cancer Research UK

Your research papers will be:

- available free of charge to the entire biomedical community

- peer reviewed and published immediately upon acceptance

- cited in PubMed and archived on PubMed Central

- yours - you keep the copyright 